CENTRO UNIVERSITÁRIO DE BRASÍLIA - UNICEUB

PROGRAMA INSTITUCIONAL DE BOLSAS DE INICIAÇÃO CIENTÍFICA (BOSISTA - PIC/JÚNIOR)

A PREPARAÇÃO DAS INSTITUIÇÕES DO ENSINO SUPERIOR PARA RECEBER ALUNOS DA TERCEIRA IDADE

BRASÍLIA

2020 


\section{A PREPARAÇÃO DAS INSTITUIÇÕES DO ENSINO SUPERIOR PARA RECEBER ALUNOS DA TERCEIRA IDADE}

Relatório Final de pesquisa a ser apresentado à Assessoria de PósGraduação e Pesquisa como requisito para conclusão do Programa de Iniciação Científica do UniCEUB, ciclo 2019/2020.

BRASÍLIA

2020 


\section{RESUMO}

Este trabalho diz respeito à Terceira Idade e teve como objetivo verificar a preparação (física, psicológica e pedagógica) de três Instituições de Ensino Superior para receber, em seus cursos, alunos desta faixa etária. Atualmente, a população da terceira idade tem crescido consideravelmente e, no Brasil, a melhoria das condições de desenvolvimento da população proporcionou um aumento da expectativa média de vida. Apesar de ser um ponto positivo, pode também ser um problema, já que o país e o mercado produtivo não estão adaptados para atender a essa população, em seus problemas ligados à saúde, educação, comércio, indústria, lazer, esportista e cultural, o que se constitui em um grande desafio. O método utilizado neste estudo foi a pesquisa qualitativa, e para análise e discussão dos dados foram utilizados os pressupostos da epistemologia qualitativa proposta por González Rey. O instrumento de pesquisa utilizado foi a entrevista semiestruturada, realizada com 15 alunos (de três Instituições de Ensino Superior Particular) e com três gestores (2 de Instituições de Ensino Superior Particular e 1 da pública), todos do Distrito Federal. Não houve seleção prévia dos participantes da pesquisa, sendo o critério para participação o de conveniência. Devido à Covid-19, as perguntas foram feitas por telefone e as respostas gravadas. Antes, foi lido o TCLE e solicitada a aquiescência ou não, de forma oral. Todos os participantes afirmaram se sentir bem, estando na terceira idade, e interessados em aprender. As opiniões sobre o fato de as instituições estarem ou não preparadas para receber alunos da terceira idade foram divergentes. Entretanto, como problemas apontados: muitos idosos não sabem lidar com computador; não há atendimento dos professores de que a cognição do aluno é mais baixa; há pessoas com problemas emocionais; necessidade de mais espaços no estacionamento e letras pequenas nas provas. Apenas um gestor sabia o número de alunos idosos da instituição. Apesar de os gestores dizerem que a instituição está preparada para receber alunos da terceira idade, somente duas das instituições têm bolsa para estes alunos. Notou-se com este trabalho que ainda não há a preocupação das IES com os alunos idosos. Não existe a percepção de que, com o aumento da expectativa de vida, eles estão cursando o ensino superior, como uma segunda graduação ou como a primeira. Os idosos sentem necessidade de voltar a estudar até porque, segundo um deles, o cérebro tem que ficar em atividade. Com relação à adaptação física, pedagógica e psicológica, todos deram a entender que as adaptações não foram realizadas especificamente aos alunos desta faixa etária, mas a todos com problemas, e até afirmaram que eles não diferem dos outros estudantes, sendo tratados como qualquer aluno. Uma instituição afirmou que existem grupos de pesquisa, disciplinas e ações de extensão na área. É muito importante este tipo de pesquisa, para gerar informação para as escolas e para que se preparem. Uma afirmação muito séria percebida foi que alguns disseram que de uma forma geral as universidades não estão preparadas para lidar com as diferenças.

Palavras-chave: IES e terceira idade. Ensino Superior e Idosos. Preparação das IES. 


\section{SUMÁRIO}

\section{INTRODUÇÃO 5}

\section{JUSTIFICATIVA 6}

\section{OBJETIVOS 7}

3.1 OBJETIVOS GERAIS 7

3.2 OBJETIVOS ESPECÍFICOS 7

3.3 HIPÓTESE DO TRABALHO 7

\section{FUNDAMENTAÇÃO TEÓRICA 8}

4.1 CONCEITUAÇÃO E CARACTERÍSTICAS DA 3 $3^{\mathrm{a}}$ IDADE 8

4.2 LEGISLAÇÃO SOBRE A 3a IDADE 9

4.3 O AMBIENTE FÍSICO E SUA ADEQUAÇÃO À 3a IDADE 10

4.4 NECESSIDADES PEDAGÓGICA, INTELECTUAL, ESPORTISTA, SOCIAL, CULTURAL E EMOCIONAL DA 3a IDADE 12

4.5 PROPOSTAS DE ADEQUAÇÃO DAS INSTITUIÇÕES DE ENSINO À $3^{a}$ IDADE 13

5 PROCEDIMENTOS METODOLÓGICOS 15

6 ANÁLISE E DISCUSSÃO DOS DADOS/ RESULTADOS ALCANÇADOS 16

6.1 PRIMEIRO SEMESTRE DO PROJETO 16

6.2 SEGUNDO SEMESTRE DO PROJETO 20

7 CONCLUSÕES 28

REFERÊNCIAS 30

APÊNDICES - ROTEIROS DE ENTREVISTA 32 


\section{INTRODUÇÃO}

O envelhecimento ocorre gradativamente ao longo da vida, e sua população tem aumentado consideravelmente ao longo dos anos. No Brasil, a melhora das condições de desenvolvimento da população proporcionou um aumento da expectativa média de vida. Apesar de ser um ponto positivo, pode também ser um problema, já que o país e o mercado produtivo não estão adaptados para atender a essa população e suas necessidades. De acordo com o artigo $1^{\circ}$ do Estatuto do Idoso, Lei $n^{\circ} 10.741$ (BRASIL, 2013), é estabelecido como idosa as pessoas com 60 anos ou mais.

A OMS (Organização Mundial da Saúde) estima que, até 2025, o Brasil será o sexto país do mundo em número de idosos e este aumento precisa ser contemplado adequadamente pelos diversos setores da sociedade (WHO, 2005). Esse acréscimo no número de idosos está ligado diretamente ao acesso a serviços como saúde, saneamento, entre outros. Porém, paralela a essas melhorias está a dificuldade de acesso a equipamentos, atendimentos e espaços públicos apropriados, que essa população enfrenta. As dificuldades nos deslocamentos e a acessibilidade interferem negativamente na independência e na boa qualidade de vida do idoso, também nas atividades cotidianas como: compras, lazer e entretenimento, cuidados com a saúde, interação social com a família e com as pessoas no geral. Nesse sentido, todos os setores da sociedade precisam se preparar para receber esta população, quais sejam, os ligados à saúde, educação, comércio, indústria, lazer, esportista, social, cultural, dentre outros.

O tema desta pesquisa consistiu em verificar o desempenho das Instituições de Ensino Superior (IES) em relação ao seu preparo físico-ambiental e pedagógico para receberem alunos na terceira idade. Procurou analisar se as IES estavam devidamente adaptadas e equipadas para oferecer o suporte necessário a eles. Discutiu as necessidades pedagógica, intelectual, social, cultural e emocional da terceira idade no âmbito do ensino superior, além de propostas de adequação dessas instituições de ensino em relação aos idosos. 


\section{JUSTIFICATIVA}

É importante destacar que no Brasil, a porcentagem atual de 12,5\% de idosos, deve alcançar os $30 \%$ até a metade do século, em breve seremos considerados uma nação envelhecida, passando de 24,4 milhões de idosos para quase 70 milhões em 2050 (BRASIL.IBGE, 2011). Conforme o Relatório Mundial de Saúde e o Envelhecimento (OMS, 2015), em função do Dia Internacional do Idoso, o número de pessoas com mais de 60 anos no país deverá crescer muito mais rápido do que a média internacional. No mundo, a quantidade de idosos vai duplicar até $\mathrm{o}$ ano de 2050, mas no Brasil ela quase triplicará.

Segundo a CODEPLAN (DF, 2019), a população do Distrito Federal em 2030 será de 3,4 milhões de habitantes. Em 2010, os idosos representavam 7,6\%; em 2030, o índice mais que dobrará e chegará a 16,6\%.

Vários setores do Brasil e do mundo, como hotelaria, cinema, vestuário, alimentício, marketing, propaganda, entre outros, estão atentos a essa nova realidade e em busca de se adequarem ao gosto e às necessidades da população idosa. Porém, elaborar estratégias sociais e públicas para preservar a qualidade de vida, moradia e saúde desta população é um grande desafio. "Precisamos repensar nossas cidades. Mais de 900 milhões de idosos estarão vivendo nas cidades a partir de 2050, mas nossas cidades não estão preparadas para essa revolução demográfica global", explicou a especialista independente de Direitos Humanos da ONU, Rosa Kornfeld-Matte (ONU, 2015, p.1).

Outro fator que, especialmente para os idosos, é determinante, é o ambiente social, o meio em que vivem e como vivem, sendo a aprendizagem permanente, o acesso à educação, a proteção contra violência e maus-tratos externos e domésticos, os principais. O oposto dessas medidas aumenta os riscos de deficiências e morte precoce, daí a importância deste trabalho. O seu problema principal foi, portanto, o questionamento: as instituições de ensino superior encontram-se adaptadas para receber alunos da terceira idade? 


\section{OBJETIVOS}

\subsection{OBJETIVO GERAL}

O objetivo geral deste trabalho consistiu em verificar a preparação (física e pedagógica) de uma Instituição do Ensino Superior para receber, em seus cursos, alunos na terceira idade.

\subsection{OBJETIVOS ESPECÍFICOS}

Os objetivos específicos previstos para esta pesquisa foram:

- Caracterizar a terceira idade do ponto de vista físico, intelectual, emocional, social, cultural e pedagógico;

- Verificar a preparação do ambiente físico para receber os alunos da terceira idade;

- Perceber outras adaptações realizadas pelas instituições (pedagógicas, apoio intelectual, emocional e social) para alunos da terceira idade;

- $\quad$ Propor adaptações necessárias para recepção dos alunos da terceira idade, pelo Ensino Superior.

\subsection{HIPÓTESE DO TRABALHO}

Ressalta-se que, por ser este trabalho uma pesquisa predominantemente de cunho qualitativo, não há obrigatoriedade na elaboração de hipóteses, uma vez que neste tipo de pesquisa o seu curso poderá ser alterado, desde que seja para se obter melhores resultados, atingindo assim seus objetivos. Entretanto, como a hipótese poderia ser usada e como os pesquisadores têm uma ideia provável de qual resultado irá ser alcançado, propôs-se a seguinte hipótese:

- As instituições de ensino superior do Distrito Federal, tanto segundo o ponto de vista de seus alunos da terceira idade, quanto dos seus gestores, não se encontram preparadas para receber esta faixa etária em seus recintos. 


\section{FUNDAMENTAÇÃO TEÓRICA}

\subsection{CONCEITUAÇÃO E CARACTERÍSTICAS DA 3a IDADE}

Apesar de no Brasil, a pessoa ser considerada idosa a partir dos 60 anos, é importante ressaltar que a idade cronológica não é, sozinha, um marcador preciso para as mudanças que acompanham o envelhecimento. As mudanças também podem acontecer e variam de acordo com o estado de saúde, nível de escolaridade, nível econômico e social, participação na comunidade, além dos níveis de independência entre pessoas mais velhas que possuem a mesma idade (OMS, 2015, p. 6). Portanto, ao se pensar em políticas e programas para os idosos é necessário que seja feito o planejamento baseado não somente na idade cronológica, mas também nas condições psíquicas e sociais envolventes, caso contrário, a política poderá ser até mesmo discriminatória e não favorecer de fato para o bem-estar da terceira idade.

Quanto às mudanças físicas na terceira idade, sabe-se que hoje elas são muito variáveis. A nutrição, exercícios, saneamento e poluição ambiental poderão ser causas do aumento da expectativa de vida. Conforme Papalia e Olds (2013, p. 502), "estilos de vida mais saudáveis podem permitir que um número cada vez maior de jovens e adultos de meia-idade da atualidade mantenham um nível elevado de funcionamento físico em boa parte da terceira idade". Este também é o caso do funcionamento do cérebro do idoso, que muda pouco, no caso de ser uma pessoa saudável. Há às vezes um funcionamento mais lento, onde as pessoas pedem para repetir a informação dada. E, também, poderá, na opinião dessas autoras, haver o "reflorescimento" para compensar perdas e encolhimento, podendo ser criadas novas sinapses ou conexões.

Em relação aos aspectos sensório e psicomotor na terceira idade, embora alguns sentem uma profunda transformação nestes aspectos, para outros, não há praticamente mudanças. Também, conforme Papalia e Olds (2013, p. 503), "as novas tecnologias, como cirurgia corretiva para cataratas e aparelhos auditivos ou implantes cocleares para corrigir perdas auditivas, ajudam muito idosos a evitar essas limitações".

O funcionamento sexual no idoso também não sofre grandes mudanças, podendo haver rica diversidade de experiência sexual em boa parte da terceira idade. Papalia e Olds (2013) afirmam que, pessoas que tiveram vida sexual ativa quando jovens, tenderão a ter vida sexual ativa também na terceira idade, sendo, 
portanto, o aspecto mais importante a considerar, a manutenção da vida sexual ao longo dos anos.

À medida que as pessoas envelhecem elas se tornam mais suscetíveis a doenças, principalmente às relacionadas ao coração. Entretanto, conforme já salientado, as chances de a pessoa chegar à terceira idade saudável e com boa forma, vai depender do seu estilo de vida, principalmente da alimentação e das suas atividades físicas.

\subsection{LEGISLAÇÃO SOBRE A $3^{\mathrm{a}}$ IDADE}

Com o crescimento do número de idosos se tornando mais expressivo ao longo dos anos, viu-se a necessidade da criação de uma legislação que fosse especificamente direcionada a eles. No Brasil, foi criado o Estatuto do Idoso, uma Lei Federal, de $n^{\circ}$ 10.741, de $1^{\circ}$ de outubro de 2003 (BRASIL, 2013), destinada a regulamentar os direitos assegurados às pessoas com idade igual ou superior a 60 (sessenta) anos que vivem no país. Com relação ao tema desta pesquisa este estatuto assegura, além de outros direitos do idoso, o acesso à educação como direito social garantido. Este escrito está evidenciado no Capítulo V da Educação, Cultura, Esporte e Lazer, nos artigos 20 e 21, a saber:

Art. 20. O idoso tem direito à educação, cultura, esporte, lazer, diversões, espetáculos, produtos e serviços que respeitem sua peculiar condição de idade.

Art. 21. O Poder Público criará oportunidades de acesso do idoso à educação, adequando currículos, metodologias e material didático aos programas educacionais a ele destinados. (BRASIL, 2013).

capacidade visual. (BRASIL, 2013).

Para atender aos critérios do Estatuto do Idoso, foram criados alguns projetos de lei que contemplassem os idosos na educação, como, por exemplo, o Projeto de Lei n 601, de 2015 (SAMPAIO, 2015), o qual altera a Lei no 11.096, de 13 de janeiro de 2005, que institui o Programa Universidade para Todos (Prouni), e a Lei no 12.513, de 26 de outubro de 2011, que institui o Programa Nacional de Acesso ao Ensino Técnico e Emprego (Pronatec), para criar política de oferta de oportunidades de estudo para indivíduos com idade igual ou superior a 60 anos.

Também estão previstas políticas educacionais para idosos no vigente Plano Nacional de Educação (PNE) - Lei no 13.005, de 25 de julho de 2014, ao dispor na estratégia 9.12 o seguinte: considerar, nas políticas públicas de jovens 
e adultos, as necessidades dos idosos, com vistas à promoção de políticas de erradicação do analfabetismo, ao acesso a tecnologias educacionais e atividades recreativas, culturais e esportivas, à implementação de programas de valorização e compartilhamento dos conhecimentos e experiência dos idosos e à inclusão dos temas do envelhecimento e da velhice nas escolas (BRASIL.DIRED, 2014).

A Política Nacional do Idoso (Lei № 8.842/94) (BRASIL.MDS, 1994) também apresenta considerações sobre a pessoa idosa e a educação, como disposto no Capítulo IV - Das Ações Governamentais, Artigo 10 - III) na área de educação:

a) adequar currículos, metodologias e material didático aos programas educacionais destinados ao idoso;

b) inserir nos currículos mínimos, nos diversos níveis do ensino formal, conteúdos voltados para o processo de envelhecimento, de forma a eliminar preconceitos e a produzir conhecimentos sobre o assunto;

[...]

e) desenvolver programas que adotem modalidades de ensino à distância, adequados às condições do idoso;

f) apoiar a criação de universidade aberta para a terceira idade, como meio de universalizar o acesso às diferentes formas do saber.

Apesar do conteúdo disposto nessas leis, não é isso que se observa na maioria das instituições de ensino superior. Além de ambientes não preparados fisicamente e que não respeitam a condição de idade dos idosos, as instituições não oferecem uma metodologia educacional direcionada para a terceira idade que se adeque às necessidades e condições específicas dessa faixa etária. A inexistência de uma política educacional específica para a terceira idade no Brasil pode dificultar o acesso deles ao ensino superior e a sua permanência neste. (REIS; MEIRA; MOITINHO, 2018).

\subsection{O AMBIENTE FÍSICO E SUA ADEQUAÇÃO À $3^{\mathrm{a}}$ IDADE}

Observando as cidades brasileiras, percebe-se que nem sempre seus espaços são acessíveis a todas as pessoas que lá vivem. A sociedade vive em um meio projetado para pessoas jovens e que não apresenta nenhuma dificuldade de locomoção ou mobilidade reduzida. O resultado disso são as dificuldades e perigos encontrados nos ambientes urbanos onde os idosos circulam. (FREIRE JÚNIOR et al, 2013). O que se constata atualmente com relação ao ambiente físico e sua adequação à terceira idade é que há uma 
lacuna na proposta de espaços públicos e edificações apropriadas aos idosos, de forma integrada à cidade.

Em muitos casos, é comum que projetos destinados a essa faixa etária promovam a segregação e o isolamento das pessoas, enquanto são várias as áreas ociosas e centrais, dotadas de infraestrutura. Programas habitacionais voltados à população de interesse social (e dentro deste conjunto também se considera a população idosa) usualmente são construídas em áreas afastadas de centros urbanos, gerando graves problemas de mobilidade e acessibilidade.

Dentre os principais fatores de risco para a população idosa estão as doenças crônicas e também os relacionados ao ambiente físico. Os problemas físicos do espaço representam um grande risco, dentre os quais, o pior está no espaço mal planejado, sem acessibilidade, em ambientes de pouca iluminação, pisos irregulares ou escorregadios, falta de corrimão de apoio, entre outros. (OMS, 2015, p. 28). Ambientes físicos favoráveis auxiliam a relação de independência das pessoas em processo de envelhecimento, elementos que tragam riscos a essa população devem ser corrigidos ou retirados, onde não existem, devem ser implantados. (OMS, 2015, p. 27).

Segundo o Sistema Único de Saúde (SUS), a cada ano são registrados gastos crescentes com o tratamento de fraturas em pessoas idosos (MINHA VIDA, 2008). De acordo com a Sociedade Brasileira de Geriatria e Gerontologia, a queda é o mais sério e frequente acidente doméstico que ocorre com os idosos e a principal etiologia de morte acidental em pessoas acima de 65 anos, tornando imprescindível que as edificações estejam devidamente equipadas e adaptadas para fornecer todo o suporte necessário às pessoas da terceira idade.

Os problemas físicos do espaço representam um grande risco, dentre os quais, o pior está no espaço mal planejado, e principalmente sem acessibilidade. Acessibilidade não apenas prejudicada por barreiras físicas, mas acessibilidade no que diz respeito a espaços públicos e urbanos de qualidade, a equipamentos e serviços adequados às suas necessidades. Por esse motivo, dentre os sujeitos em desvantagens, os idosos se apresentam como um público representativo e muitas vezes se veem confinados em suas casas, privando-se de sua participação no convívio social (FREIRE JÚNIOR et al, 2013). Ambientes físicos adequados à idade favorecem a relação de independência da pessoa em processo de envelhecimento. Fatores ligados a necessidades de saúde e de 
segurança são também muito relevantes, elementos que tragam riscos a essa população devem ser corrigidos ou retirados, onde não existem elementos favoráveis, esses devem ser implantados.

\subsection{NECESSIDADES PEDAGÓGICA, INTELECTUAL, ESPORTISTA, SOCIAL, CULTURAL E EMOCIONAL DA $3^{\mathrm{a}}$ IDADE}

A educação de adultos, segundo Salvador et al (2010), possibilita sua conscientização em relação ao seu estado e à sua posição, levando-o a superar situações injustas e de opressão. O aumento de sua expectativa de vida faz com o que ele deseje retornar à escola, ou mesmo completar seus estudos. Segundo ainda este autor, o idoso entra na escola com diferentes experiências vividas e interesses particulares que os conduzem a um processo formativo peculiar, e que, tudo isso, interagindo com a resposta educativa que recebe, sendo ela mais ou menos ajustada à sua especificidade, configura o processo educativo em seu êxito ou inadequação. (SALVADOR et al, 2010, p. 190).

Os idosos não podem deixar de exercitar o físico, mas também a capacidade cognitiva, para que não percam essas funções. De acordo com Papalia e Olds (2013, p. 519), é muito importante que o idoso se envolva na leitura, conversação, palavras cruzadas, jogo de cartas ou xadrez, ou, deve voltar para a escola. A inexistência de uma política educacional específica para a terceira idade no Brasil pode dificultar o acesso deles ao ensino superior e a sua permanência neste. (REIS; MEIRA. MOITINHO, 2018).

Normalmente, na terceira idade, a tendência é verificar o que falta nesta fase da vida, mas não as suas experiências, conhecimentos, maturidade, juízo e estabelecimento. Vê-se, no entanto, que existem concretamente mudanças fisiológicas nessa idade, conforme, Salvador et al (1999, p. 190), "na velocidade, nos tempos de reação, no vigor, na visão e na audição".

Quanto ao aspecto mental da terceira idade, existe a probabilidade de ocorrerem problemas, que também poderão ser postergados ou minimizados com um estilo de vida saudável. Mesmo assim, a maioria tem condições de fazer compras, lidar com o dinheiro, fazer comida ou realizar tarefas domésticas. Mesmo aqueles em asilos, ainda poderão ter autonomia para caminhar, fazer sua higiene pessoal, alimentar-se (PAPALIA; OLDS, 2013). 
Com relação a seu aspecto cognitivo, "as pessoas mais velhas podem e efetivamente continuam a adquirir novas informações e habilidades e são capazes de lembrar e usar bem aquelas que já conhecem", segundo Papalia e Olds (2013, p. 511-517). E, ainda para estes autores, a inteligência, embora "algumas habilidades - principalmente em tarefas não-verbais e na resolução de problemas não-familiares - possam diminuir, outras permanecem estáveis ou até mesmo são aperfeiçoadas durante a maior parte da vida adulta". Neste sentido, vai haver muita diferença individual e declínios também podem ser prevenidos. Em relação à memória, eles afirmam que, na memória de curto prazo, existem dois componentes (a primária, onde são guardadas pequenas quantidades de informações recém adquiridas, que conserva a sua eficiência com a idade); e a de operação (armazena e manipula a informação, o que demanda mais esforço mental).

No que se refere ao aspecto emocional e social da terceira idade, Papalia e Olds (2013, p. 531-552), encontraram correlação positiva em relação ao bemestar e à religiosidade, ou seja, que sua autoestima atinge o "máximo quando seu comportamento é consistente com suas crenças, seja lá quais forem"; também perceberam que o contato, principalmente com a família, é mais importante que antes, bem como terem pessoas que cuidam bem deles; que na ausência dos filhos, muitas vezes vizinhos e amigos, passam a ter suas tarefas, o que compensa a falta de familiares; referem-se também ao ato de que a maioria vive com familiares, quer sejam filhos ou parentes, mas que a maioria prefere viver em suas casas e que os relacionamentos humanos são muito importantes para eles, embora declinem na velhice. Concluem afirmando que as "amizades são importantes para o prazer, intimidade e apoio para enfrentar os problemas de envelhecimento".

\subsection{PROPOSTAS DE ADEQUAÇÃO DAS INSTITUIÇÕES DE ENSINO À $3^{a}$ IDADE}

Tendo em vista as dificuldades avaliadas, constatou-se que não há instituições de ensino dirigidas aos idosos, que atendam especificamente suas necessidades e peculiaridades enquanto sujeitos sociais (REIS; MEIRA; MOITINHO, 2018). Por esse motivo, considerou-se a necessidade de elaborar 
propostas de soluções a fim de obter uma infraestrutura adequada nessas edificações, adaptadas aos alunos idosos.

Com relação aos ambientes físicos das instituições de ensino superior, a mobilidade e a acessibilidade são os fatores de relevância que devem ser considerados por elas, ao receberem alunos nessa faixa etária, pois, devido aos desafios físicos que as pessoas idosas enfrentam, como dificuldade na locomoção, irão interferir no ingresso e na circulação adequados dessas pessoas nas instituições. A preocupação com essa relação idoso-ambiente é particularmente importante, uma vez que o planejamento do ambiente construído e a acessibilidade urbana são temas emergentes relacionados ao estudo da velhice e do envelhecimento (FREIRE JÚNIOR et al, 2013), temas estes que devem ser considerados na criação e desenvolvimento de instituições de ensino superior que têm estudantes na terceira idade.

No Brasil, a norma técnica NBR norma técnica NBR 9050/2004 (ABNT, 2015) estabelece parâmetros para adequação dos ambientes urbanos, além da concepção de desenho universal, que tem sido implantada nas discussões sobre acessibilidade. Algumas especificações da norma, como o uso de rampas de acesso, possuindo corrimão de duas alturas nos dois lados; acessos livres de quaisquer obstáculos de forma permanente; vagas de estacionamento para pessoas com deficiência e para idosos, a uma distância máxima de $50 \mathrm{~m}$ até rampas e entradas acessíveis; são alguns dos exemplos de propostas de adequação que as instituições podem adotar para proporcionar um ambiente favorável aos alunos na terceira idade. Essas iniciativas, além de facilitarem e melhorarem a interação dos idosos com o ambiente físico da edificação, também proporcionam um sentimento de independência e confiança, pois o ambiente permite que o idoso consiga realizar suas atividades sozinho.

A respeito da educação, as instituições de ensino superior não fazem diferenciação pedagógica entre os alunos. Por mais que os próprios idosos considerem um ensino igualitário, sem distinção, positivo, pois não se sentem diferentes, as pesquisas apontadas no referencial teórico desta, evidenciam que com o passar dos anos os aspectos cognitivos são alterados, e consequentemente, o processo de aprendizagem. A não adoção por parte das instituições de ensino, de métodos adaptados, evidenciam a dificuldade no processo de aprendizagem dos alunos idosos. Essa negligência consta até 
mesmo na Lei de Diretrizes e Bases da Educação Nacional (LDB) Lei 9.394/96 (BRASIL.MEC, 1996), uma das principais leis brasileiras da educação. Nela é citada a educação de jovens e adultos, sem diferenciar a velhice da vida adulta como fase que demanda atenção, diretrizes e metodologias próprias, a fim de transmitir conteúdos de maneira mais eficiente para este grupo.

\section{PROCEDIMENTOS METODOLÓGICOS}

O método utilizado neste estudo foi a pesquisa qualitativa, uma vez que esta proporciona maiores subsídios de alcance dos objetivos específicos, no caso a adequação das IES para receber alunos da terceira idade, além de oferecer maiores possibilidades de interpretação. Vilela Junior (2010) afirma que o objeto principal da pesquisa qualitativa é interpretar o fenômeno que observa.

Para análise e discussão dos dados foram utilizados os pressupostos das abordagens qualitativas e quantitativas, tendo sido adotada prioritariamente a epistemologia qualitativa proposta por González Rey (2005, p. 5-8), que a conceitua como sendo aquela que "defende o caráter construtivo interpretativo do conhecimento, o que de fato implica compreender o conhecimento como produção e não como apropriação linear de uma realidade que se nos apresenta".

O instrumento de pesquisa utilizado foi a entrevista semiestruturada, feita com quinze alunos idosos de instituições de ensino superior particular, bem como de três gestores (dois de escolar particular e um da escola pública (APÊNDICES).

Não houve seleção prévia dos participantes da pesquisa. O critério para participação foi o de conveniência, ou seja, pessoas dentro dos critérios da pesquisa, que tiveram o interesse em participar da mesma. No primeiro semestre do projeto, as entrevistas foram feitas de forma presencial. Entretanto, devido à Covid-19, no segundo semestre do projeto, as perguntas foram feitas por telefone e as respostas gravadas. Antes, foi lido o TCLE e solicitada a aquiescência ou não, de forma oral. 


\section{ANÁLISE E DISCUSSÃO DOS DADOS/ RESULTADOS ALCANÇADOS}

\subsection{PRIMEIRO SEMESTRE DO PROJETO}

Após todas as providências junto ao Comitê de Ética do UniCEUB e aprovação do projeto, antecedidas por contatos junto à instituição pesquisada que assinou o Termo de Aceite Institucional, partiu-se para a aplicação das entrevistas. Realizou-se, então, as entrevistas com o gestor e com cinco alunos da terceira idade no UniCEUB, cuja análise e discussão dos resultados serão transcritos abaixo.

- Alunos

Perguntados como se sentiam fisicamente na terceira idade, responderam que estão bem. Um dos entrevistados relata que "estar feliz é mentira, óbvio que gostaria de estar mais jovem, porém me sinto bem."

Quando foi feita a pergunta sobre o porquê de cursarem o ensino superior, um dos argumentos interessantes foi: "Me aposentei há alguns anos e como sou ativa, não gosto de ficar sem me mexer e acabei decidindo que voltaria a estudar." Outro afirmou: "O cérebro não pode parar e precisamos sempre estar em movimento, se não estudasse estaria fazendo outra atividade."

Com relação à satisfação com seus cursos eles responderam que "acha seu curso desafiador;" "está satisfeito com seu curso;" e "gosto do que aprendi." Somente um afirmou que nem sempre está satisfeito com o curso.

Questionados se a Instituição de Ensino ofereceu atendimento especial para eles e todos responderam que "não", que foram tratados de forma normal. É importante salientar que as instituições de ensino superior devem se adequar a um novo tempo, pois, conforme Who (2005), a OMS estima que, até 2025, o Brasil será o sexto país do mundo em número de idosos e este aumento do número de anos de vida precisa ser contemplado adequadamente pelos diversos setores da sociedade"

Foi perguntado se alguma vez teve algum tipo de dificuldade devido à idade disseram: "Não." Um justificou que: "Fui bem recebida." Sobre o quesito relacionamento com os colegas, afirmaram: "Excelente"; "Muito bom." Desabafou:" Pensei que não iriam me receber bem, mas acabei me enganando." Sobre o relacionamento com os professores, os alunos disseram ser ótimo e normal, e um dos alunos disse que "julgava que os professores iriam ter um certo diferencial por conta da idade, mas eles já estão acostumados". 
Sobre as adaptações físicas na instituição, para receber os alunos da terceira idade, os alunos disseram que adaptações próprias para idosos não têm. Um aluno disse que nunca precisou usar esses lugares adaptáveis, e outros dois alunos disseram que têm adaptações para deficiência física, mas que servem para a terceira idade também. Segundo a OMS (2015), no mundo, a quantidade de idosos vai duplicar até o ano de 2050, mas no Brasil ela quase triplicará.

Sobre o ponto de vista dos alunos, na questão da preparação educacional da instituição, para receber pessoas na terceira idade, os alunos disseram que sim. Um aluno afirmou que, para isto, "basta ter vontade de aprender"; outro afirmou que "não é necessário diferenciar a terceira idade"; ainda um afirmou que "sempre que tenho alguma dificuldade procuro a secretaria e eles me ajudam nessa questão". Outro aluno disse que acha que está preparada e um que não tem dificuldade, mas que outros podem ter necessidades. O Estatuto do Idoso, uma Lei Federal, de № 10.741 (BRASIL, 2003), de 1ํ de outubro de 2003, em seu Capítulo V da Educação, Cultura, Esporte e Lazer, o seu artigo 20 e 21 reza:

Art. 20. O idoso tem direito à educação, cultura, esporte, lazer, diversões, espetáculos, produtos e serviços que respeitem sua peculiar condição de idade.

Art. 21. O Poder Público criará oportunidades de acesso do idoso à educação, adequando currículos, metodologias e material didático aos programas educacionais a ele destinados.

Sobre a necessidade de atendimento específico: todos os alunos disseram que não precisaram. Sugestões dos alunos para a instituição atendêlos em questões físicas, pedagógicas, emocionais e sociais: dois alunos disseram que não há necessidade e um disse que a instituição atende muito bem; um completou: "devia nos tratar como qualquer estudante". Outros dois alunos deram sugestões, sobre questões físicas e pedagógicas: "aulas em locais mais baixos, pois todos usam o elevador"; "nas avaliações os alunos de terceira idade deveriam ser vistos de maneira diferente"; "poderiam ter pessoas específicas para nos motivarem, um programa de incentivo". Uma última aluna defendeu que considera a terceira idade, a partir dos 80 anos, pois tem 60, e é bem ativa. Segundo Reis, Meira e Moitinho (2018), a inexistência de uma política educacional específica para a terceira idade no Brasil pode dificultar o acesso deles ao ensino superior e a sua permanência neste. 
Portanto, ao se pensar em políticas e programas para os idosos é necessário que seja feito o planejamento baseado não somente na idade cronológica, mas também nas condições psíquicas e sociais envolventes, caso contrário, a política poderá ser até mesmo discriminatória e não favorecer de fato para o bem-estar da terceira idade.

\section{- Gestor}

O gestor de uma das instituições de ensino superior particular não preencheu os dados de identificação do questionário, mas quando perguntado se ele sabia o número de pessoas acima de 60 anos que estudavam na instituição, ele afirmou que sim, mas não citou o total. Quanto ao fato se a instituição estava preparada para receber esses estudantes, ele afirmou que sim, que estava "totalmente preparada, visto que possuímos total estrutura para atender suas necessidades, sendo elas estruturais ou sociais". Segundo Buksman et al. (2008), a participação dos fatores de risco ambientais pode alcançar, conforme estudo, até $50 \%$ das quedas entre os idosos da comunidade. Dentre tais fatores podemos citar: iluminação inadequada, superfícies escorregadias, degraus altos ou estreitos, obstáculos no caminho (móveis baixos, pequenos objetos, fios), ausência de corrimãos em corredores e banheiros, entre outros.

Ao ser inquirido se a instituição realizou alguma adaptação na instituição para receber as pessoas da terceira idade ele respondeu que sim, "mas não exclusivamente para pessoas da terceira idade, o UniCEUB possui uma estrutura adaptada para todos, visto que nossos banheiros, salas de aula e corredores foram projetados para atender além da melhor idade, os portadores de necessidade especial e também as alunas em maternidade (fraldário). Não somente no ambiente físico, a instituição conta com o suporte à acessibilidade $e$ o apoio psicopedagógico, sendo realizados pelo Núcleo de Apoio ao Discente (NAD)". Ainda foi perguntado especificamente se havia alguma preocupação em relação ao ambiente físico para atender à terceira idade, e ele respondeu que sim, que conforme "respondido na questão anterior, a instituição tomou o cuidado de realizar adaptações estruturais para atender a todos, não apenas as pessoas da terceira idade". 
Sobre se a instituição possuía algum outro tipo de preocupação (pedagógica, social, emocional) para atender à terceira idade, ele respondeu que "possuímos o suporte realizado pelo NAD, que dentre outros objetivos são, permitir a acessibilidade para pessoas com deficiência, mobilidade reduzida, Apoio Psicopedagógico, entre outros". Com relação ao aspecto cognitivo, Papalia e Olds (2013, p. 511-517) afirmam que "as pessoas mais velhas podem e efetivamente continuam a adquirir novas informações e habilidades e são capazes de lembrar e usar bem aquelas que já conhecem. E, ainda para estes autores, a inteligência, embora "algumas habilidades - principalmente em tarefas não-verbais e na resolução de problemas não-familiares - possam diminuir, outras permanecem estáveis ou até mesmo são aperfeiçoadas durante a maior parte da vida adulta".

Ao ser inquirido se existia algum tipo de tratamento especial para a terceira idade, ele respondeu que "sim, possuímos o benefício da bolsa Melhor Idade, a qual oferece a diminuição de $50 \%$ (cinquenta por cento) na mensalidade". Ao ser questionado sobre se esses alunos poderiam se constituir em um problema para a instituição, ele afirmou que "de modo algum, alunos da terceira idade não constituem nenhum problema, inclusive a instituição trabalha para evitar o inverso, ou seja, garantindo que esses alunos não tenham nenhuma dificuldade, seja pedagógica, emocional, social ou estrutural". Também disse que nunca tiveram problemas relacionados aos alunos da terceira idade.

Não há, segundo o gestor, nenhum benefício à instituição em receber alunos na terceira idade, uma vez que para ele, esses alunos, "nada mais são que alunos".

- Análise dos dados de gestor e alunos

Foi interessante observar que o gestor afirmou que a instituição se encontrava totalmente preparada para receber alunos da terceira idade, ressaltando que "possuímos total estrutura para atender suas necessidades, sendo elas estruturais ou sociais". Entretanto, os alunos, aos serem questionados se a instituição ofereceu algum tipo de atendimento especial, salientaram que não, que "foram tratados de forma normal". O gestor atribui ao NAD tal suporte, mas este cuida atualmente dos alunos com deficiência e não da terceira idade. 
O gestor salienta que ao preparar a instituição para atender alunos com deficiência, terminou por prepará-la também para receber os alunos da terceira idade, o que também foi reforçado pelos alunos. Inclusive o gestor voltou a citar - NAD para oferecer aos idosos atenção pedagógica, social e emocional, repetindo que o NAD não está desempenhando esta função. Citou também que os alunos da terceira idade são alunos como os outros, que eles não se constituem em problema para a instituição, e que nunca tiveram problemas com esses alunos.

Entretanto, um aspecto positivo da instituição é a oferta de $50 \%$ de desconto, pela bolsa Melhor Idade.

Apesar da maioria citar que não precisa de atendimento específico, que nunca precisaram de atendimento voltado à terceira idade, sugeriram que a instituição fornecesse "aulas em locais mais baixos, pois todos usam o elevador"; que "nas avaliações os alunos de terceira idade, deveriam ser vistos de maneira diferente"; e "poderiam ter pessoas específicas para nos motivarem, um programa de incentivo".

Segundo a NBR 9.050 (ABNT, 2015), implantação de rampas de acesso possuindo corrimão de duas alturas em cada lado; acessos livres de quaisquer obstáculos de forma permanente; vagas de estacionamento para pessoas com deficiência e para pessoas idosas, a uma distância máxima de $50 \mathrm{~m}$ até um acesso acessível e espelhos constantes em toda a escada, são alguns dos exemplos de propostas de adequação que as instituições podem adotar para proporcionar um ambiente favorável aos alunos na terceira idade.

\subsection{SEGUNDO SEMESTRE DO PROJETO}

- Alunos

Os participantes da pesquisa, nesta segunda etapa, em sua maioria, eram constituídos de pessoas na faixa etária entre 60 e 69 anos e quase todos estavam em sua segunda graduação. Havia cinco estudantes de Psicologia, dois de Nutrição, um de Arquitetura, um de Fisioterapia e um de Serviço Social.

Em relação à profissão dos participantes, a maioria já se aposentou de seus trabalhos. Uma participante na ativa, socióloga., conta que "atualmente trabalho com consultoria e tenho um programa de Rádio-FM de Pernambuco". Com relação a isso, Veras (apud BÚFALO, 2013): 
observou, estudando e pesquisando sobre velhice, assim como visitando hospícios, alojamentos e pensões de aposentados, que as oportunidades oferecidas aos idosos eram quase inexistentes e propôs abertura das universidades a todos os idosos, a fim de oferecer-lhes programas intelectuais, artísticos, de lazer e de atividade física.

Quando perguntados sobre as suas condições psíquicas, todos disseram se sentir bem; um dos entrevistados até brincou falando: "Me sinto como um jovem de 20 e poucos anos". Outro disse: "Me sinto melhor fisicamente e mentalmente do que há 10 anos atrás". Relacionando as condições dos idosos no Brasil e seus direitos, a pesquisa sobre Envelhecimento populacional e as informações de saúde do PNAD: demandas e desafios contemporâneos, Veras e Caldas (2004) abordam que: "o Brasil hoje é um jovem país de cabelos brancos, 650 mil novos idosos são incorporados à população brasileira, a maior parte com limitações funcionais".

Sobre a decisão de cursar o ensino superior, uma das participantes falou: "resolvi fazer a inscrição para motivar minha filha". Outra participante conta que parou de estudar com 17 anos. "Não tinha ninguém para me incentivar pra continuar". Com 81 anos ela fez o supletivo e terminou o segundo grau e "hoje se diverte cursando psicologia". Com base nesse assunto, sobre "a decisão de cursar o ensino superior", na pesquisa: Aprender na terceira idade: educação permanente e velhice bem-sucedida como promoção da saúde mental do idoso, Búfalo (2013) escreve que:

Em 1974, a Universidade da Terceira Idade de Toulouse
transformou-se num programa regular, ofertando cursos de
duração de um ano. Em Nantèrre, as pessoas idosas com
apenas o curso primário, podiam frequentar as disciplinas
oferecidas aos alunos do curso superior, na mesma sala de aula,
ou seja, indivíduos com idades e formações diferentes discutiam
e trocavam ideias, relacionando-se sem qualquer obstáculo,
sendo que esse contato possibilitou a valorização dos idosos
pelos jovens. Desde então, pode-se afirmar que a procura e a
ampliação da Universidade da Terceira ldade tem crescido em
intensidade quase similar ao fenômeno da longevidade mundial.

No que se refere à satisfação em relação ao curso, do total de 10 participantes, todos mostraram-se satisfeitos e interessados em aprender. Dentre eles, 1 participante citou que "de forma geral, as graduações são superficiais, leves e tem furos, mas que pode continuar estudando, fazendo pós, cursos na área e concluir as lacunas, que na verdade, nunca estarão totalmente 
fechadas". Dois citaram que é uma oportunidade para ajudar as pessoas, e outro disse que é a sua maior paixão e que lhe dá motivo para viver. Em relação a isso, o texto Qualidade de vida na terceira idade: um conceito subjetivo (VECCHIA et al, 2005, p. 249) afirma:

Praticando a retidão e a caridade (4,93\% - 18 idosos): significa a sua satisfação em poder praticar a solidariedade e a honestidade. As unidades de registros que representam a categoria foram agrupadas de tal maneira que qualidade de vida para o idoso é, também, poder "praticar o bem junto ao seu semelhante e saber que é honesto, não prejudicando, mas ajudando o semelhante, e cumprir adequadamente suas obrigações".

Porém, 2 participantes citaram alguns pontos negativos: um falou sobre a insatisfação com alguns professores que simplesmente dão as apostilas e mandam estudar; acha que dar aula no quadro é melhor. Quanto a isso, Reis, Meire e Moitinho (2018) afirmam que,

no que se refere aos desafios para permanecer no ensino superior, Sr. João destacou a dificuldade de entender e interpretar os textos e os termos acadêmicos. Outro desafio apontado por ele se refere à didática do professor universitário: "a forma do professor ministrar aula era muito complicada, mas, a partir de algumas conversas com eles, alguns melhoraram e tornaram os conteúdos mais compreensíveis" (Sr. João, 76 anos, 14 set. 2017). Com o esforço dos docentes em ouvir os alunos e usar uma linguagem mais acessível e com a familiaridade com os textos acadêmicos por parte dos alunos, afirmou que foi possível entender mais os conteúdos propostos.

Outra participante falou que a instituição tem "[...] vertentes comportamentais que acho desatualizado [...]", mas logo ressaltou que seu propósito maior é, além de aprender, ser autorizada a fazer o que gosta, tratar a "alma dos outros" e evoluir.

Sobre o atendimento específico oferecido aos ingressantes da terceira idade ao entrar na Instituição, somente um participante afirmou com certeza que teve atendimento específico em relação à idade que é o desconto de 35\% por ter mais de 50 anos. Cinco participantes disseram que não tiveram atendimento específico, mas, apesar disso, dois deles citaram sobre as bolsas também. Um aluno citou que o único requisito que ele teve e que facilitou, foi que ele tem um outro curso superior antecedente formado, então que não precisou fazer vestibular, entrou como portador de diploma. Dois alunos disseram que quando entraram não estavam na terceira idade e um deles disse que na pandemia os 
professores e a coordenação não o deixaram ir para "campo" por conta da idade. Em relação ao assunto, o texto "A Educação para e na Terceira Idade construindo na diversidade: uma inclusão necessária", afirma que:

Os programas criados nas universidades com ações voltadas para a terceira idade são resultado de propostas realizadas pela ONU E UNESCO. No Brasil, os programas visando integrar os idosos na sociedade através de diversas atividades remetem ao SESC - SP que, em 1977, sintonizado com os movimentos educacionais da Europa, sobretudo da França, inaugurou no Brasil um novo modelo de atendimento ao idoso: as Escolas Abertas para a Terceira Idade. Estruturadas com cursos e oficinas oferecidas a esse público, visavam à atualização de informações e o desenvolvimento de novas habilidades, premissas para uma adequada adaptação a um tempo social de rápidas mudanças de valores e comportamentos. O sucesso dessa experiência inspirou a criação das Universidades Abertas à Terceira Idade, hoje espalhadas por todo o Brasil. (ALMEIDA, OLIVEIRA, 2013, p. 18590).

Em relação às dificuldades na instituição para atender à Terceira Idade, 6 participantes disseram não ter dificuldades, porém 1 participante dentre os que disseram não, contou sobre uma violência oculta que ocorreu com ela, em que uma professora negou a ajuda em um trabalho e ela acredita que seja por ela ser da terceira idade. Ela disse: "Eu não sei exatamente se houve um julgamento, um juízo de valor que ela achou que era uma coisa irrelevante pra mim, ou, o que foi efetivamente, mas isso pra mim incomodou". Ela disse também que não teve a oportunidade de conversar com a professora, mas que assim que tiver assim ela o fará. Contou também sobre quando, a mesma professora, pediu o seu currículo e ela estranhou, mas entregou mesmo assim. Ela relatou: "E aí peguei uma pasta que eu tenho de reserva com documentos com o meu currículo e entreguei pra ela, ela disse que era um livro e ficou assustada. Isso me criou duas situações. Bom eu não sei até que ponto ela fez isso assustada, não sei se ela achou que o meu currículo era muito extenso, mas me incomodou também. Aí eu pensei 'ela não é o que ela diz'”. Em relação a esse depoimento, pode-se ler no texto Desenvolvimento das habilidades sociais em idosos e sua relação na satisfação com a vida: "Eu aprendi a defender os meus direitos sem prejudicar ou ofender a pessoa em questão" (CARNEIRO; FALCONE, 20130. Outra participante, dentre os que disseram que não tiveram dificuldade, falou que para ela é porque passou muitos anos sem estudar, então é uma mudança de ritmo, mas que ela respeita seu tempo e que está lá para se divertir. Em relação a esse 
aspecto, o texto de Lemos (2013) cita que o idoso brasileiro que decide ir à faculdade "possui certa dificuldade para compreender os conteúdos das aulas, mas afirma que sempre se esforça para ter um bom desempenho. "As minhas ideias são curtas e não entendo com facilidade os conteúdos, mas a disciplina vai passando e vou aprendendo". 3 participantes falam diretamente sobre algumas dificuldades, dois falam sobre as vagas de estacionamento para idosos que são apenas três vagas específicas e um deles disse que precisa sair 1 hora antes para conseguir estacionar. Outro participante falou que o único problema no começo foi a falta de educação de algumas pessoas.

Com respeito ao relacionamento entre colegas, a maioria dos participantes relatou que tem boa convivência com seus colegas de turma e que conseguem formar grupos facilmente. Entretanto um participante ressaltou que "no começo sofri um pouco de bullying, parecia que os colegas não acreditavam que eu podia fazer o curso e me tornar um bom profissional. Contornei essa situação. Quando você é esforçado todos te respeitam." Contudo, uma participante citou que apesar da turma ser heterogênea, os alunos buscam sempre pela compatibilidade de idade, que ela se aproxima mais de pessoas de sua idade, porque se identifica mais. Pessoas de mais idade buscam ganhos emocionais e por este fato se tornam mais ponderadas ao escolher amizades. $O$ bem estar pode ser alcançado através de relações saudáveis e contatos regulares que oferecem suporte social aos idosos (DEPS, 1993 apud CACHIONI, 1998).

Em relação aos professores, todos os participantes relataram que se dão bem e que são tratados sem discriminação de idade, porém, a proximidade de interação não acontece com todos os profissionais. Há professores mais próximos que outros, para alguns entrevistados. Uma aluna relatou: "eu percebo que uns dão maior força e outros ignoram a gente até nos conhecer melhor; à primeira vista, quando vêm alunos de cabelos brancos acham que eles estão ali porque são aposentados e que não têm mais nada o que fazer; mas com o tempo eles vão percebendo que não é bem assim, que estamos ali porque somos interessados." Pode-se justificar esse tipo de relação pela qualidade dos professores e pela resiliência de se adequarem a qualquer cenário, evitando a desqualificação no âmbito e concretizando relações devido às experiências com alunos da terceira idade (ARRUDA, 2009.). 
As adaptações físicas das instituições para receber os alunos da terceira idade existem, porém, com falhas em alguns aspectos, segundo a maioria dos alunos. Os entrevistados relataram que existem rampas ou elevadores, mas que enfrentam problemas com sinalizações com letras pequenas e estacionamento com poucas vagas ou longe demais. O relato de uma aluna foi "o problema é só o estacionamento, que tenho que sair 1 hora antes de casa e atrapalha até meu jantar." Uma curiosidade é que alguns alunos ainda não sentem a necessidade de adaptações, mas comentam a necessidade para pessoas que possuem algum tipo de deficiência. No artigo 25 da Lei № 13.535 de 15 de dezembro de 2017, que alterou o art. 25 da Lei no 10.741 (BRASIL, 2017), de $1^{\circ}$ de outubro de 2003 (Estatuto do Idoso) cita que:

Parágrafo único. O poder público apoiará a criação de universidade aberta para as pessoas idosas e incentivará a publicação de livros e periódicos, de conteúdo e padrão editorial adequados ao idoso, que facilitem a leitura, considerada a natural redução da capacidade visual (lei no 13.535, de 2017).

Diante disso, a falta de adaptações físicas em universidades pode promover falhas no sistema para assistência à terceira idade, no modo como foi mencionado nas entrevistas.

Sobre a preparação da instituição do ponto de vista educacional para receber pessoas na terceira idade, de dez participantes cinco disseram que a instituição está preparada para receber pessoas da terceira idade. Dois entrevistados disseram que a faculdade possui poucas vagas de estacionamento para idosos e que, geralmente, são distantes do prédio. Alguns participantes relataram falta de adaptação ou atendimento especializado. Um dos participantes disse que muitos idosos não sabem mexer no computador; outro citou que nunca viu avaliações adaptadas para pessoas da terceira idade e que falta de desconto de mensalidade para a terceira idade. Dois participantes consideraram as rampas e elevadores estruturalmente inclusivos. $O$ participante 8 disse que não necessariamente os idosos precisam de atendimento especializado e que muitos confundem idade com incapacidade intelectual.

Em relação ao atendimento específico à terceira idade na instituição, de dez participantes cinco responderam que não receberam esse tipo de atendimento. Quatro participantes disseram que nunca precisaram de 
atendimento específico. Apenas um entrevistado relatou já ter recebido atendimento específico de psicólogos e profissionais da enfermagem.

Os profissionais da educação e da saúde precisam observar estratégias específicas para o atendimento eficiente aos idosos. A educação deve ser direcionada para a amplificação de informações com uma abordagem interdisciplinar e condizente às especificidades da terceira idade (BÚFALO, 2013).

Quando perguntados se dariam alguma sugestão à instituição do ponto de vista físico, pedagógico, emocional e social para atender à terceira idade, de dez participantes cinco disseram que tinham sugestões para a instituição do ponto de vista físico. Dentre as sugestões, quatro foram referentes aos estacionamentos, por serem poucas vagas preferenciais, pagos ou distantes dos prédios; uma foi sobre as cantinas e uma sobre a ventilação das salas de aula. Sobre a questão pedagógica, apenas dois participantes não deram sugestões. Os participantes que deram alguma sugestão falaram sobre dar mais coerência aos estudos; promover a prática ao invés de focar na teoria; material para leitura com letras maiores; mais auxílio com tecnologias e informática; apostilas com conteúdo mais completo; mais dinâmicas como debates nas aulas. Um dos participantes relatou não concordar com disciplinas EAD, pois muitos da terceira idade moram sozinhos e não possuem facilidades com as ferramentas do computador. Sobre o ponto de vista emocional, apenas três participantes deram sugestões, que foram: abrir espaços para valorização e adiantar disciplinas e discussões sobre o racismo e o bullying, manter relação de respeito, melhor compreensão dos problemas de saúde. As sugestões para o ponto de vista social foram: mais incentivo financeiro para pessoas da terceira idade, principalmente as que possuem menor renda e proporcionar maior inclusão.

As pessoas da terceira idade têm a capacidade de aprender, ao contrário do que muitos pensam. No processo educacional dos idosos, deve-se atentar aos incentivos necessários para o aprendizado, relacionando com a cultura e papel social pertencentes à terceira idade (SCORTEGAGNA; OLIVEIRA, 2010).

Cada faixa etária possui suas características e especificidades, inclusive a terceira idade. Algumas universidades possuem um programa de atendimento específico para idosos. Dentro desse programa, as necessidades específicas das pessoas da terceira idade são atendidas, visando maior qualidade 
educacional e a interação social com os mais jovens. É importante se atentar às necessidades. Sendo assim, a inclusão pedagógica, cultural e social deve acontecer no Ensino Superior (VERAS; CALDAS, 2004).

\section{- Gestor}

Os gestores das duas outras instituições de ensino superior (uma pública e outra particular), não diferiram tanto do gestor da primeira instituição. Dois deles nem sabiam o número de pessoas acima de 60 anos, que havia na instituição. Uma das instituições não oferecia descontos para alunos da terceira idade.

A instituição pública salientou que disciplinas, grupos pesquisas e ações de extensão sobre a terceira idade eram realizadas na instituição, o que se considerou um avanço neste campo de estudo.

O que foi percebido, apesar de os gestores enfatizarem que há a adaptação física da instituição para receber esses alunos, o que há são adaptações para alunos com deficiência e que acabam por servir aos da terceira idade. Não existe nenhuma proposta pedagógica para esses alunos. Conforme Fajardo (2010), Para Antonio Jordão Netto, coordenador técnico do curso da PUC, é fundamental que o curso tenha proposta acadêmica e solidez de conteúdo. "Caso contrário, corre-se o risco do curso ser apenas um 'caça-níquel'. A faculdade não é para ser uma excursão da Terceira Idade e nem um curso para velhos. É um curso para quem quer reciclar conhecimento."

Segundo Natali (2014), sobre a importância de um planejamento diferenciado:

Os cuidados com relação aos cursos destinados a esse grupo estão relacionados à oferta de um conteúdo atualizado que atenda aos interesses dessa demanda muito distinta, que favoreçam a integração dos aspectos físicos, sociais e psicológicos, oferecendo meios, condições e recursos para que os participantes possam realizar-se plenamente como pessoas que buscam a melhoria de sua qualidade de vida e processos de "ressignificação".

Os idosos são tratados como qualquer outro aluno, sem que a instituição reconheça as suas peculiaridades, seus interesses e como eles chegam na faculdade. Fajardo (2010), em seu trabalho de pesquisa, constatou que, para o coordenador executivo do curso para a terceira idade, Fauze Saadi, "os idosos 
que procuram tais atividades estão no caminho certo. 'Costumo brincar que os alunos deveriam tirar uma fotografia quando ingressam na universidade e meses depois. É quase uma cirurgia plástica sem bisturi. Além disso, a saúde melhora. Roubamos clientela dos consultórios médicos"'. A Gerontologia, um conjunto de orientações e oportunidades assumidas pelo indivíduo, e/ou, facultadas pelo meio, deverá produzir alterações na identidade dos idosos. "Novos papéis sociais e o fortalecimento de funções pessoais conquistados graças ao tempo livre serão possivelmente os instrumentos de reinvenção da identidade" (NATALI, 2014).

\section{CONCLUSÕES}

Esta pesquisa pretendeu verificar, especificamente, se a instituição de ensino superior estava preparada ou se preparando para receber a demanda da terceira idade. Acredita-se que essa adequação deva ser urgente e é muito necessária, dado o número crescente de idosos pelo mundo, no Brasil e em Brasília, pois a melhoria das condições de desenvolvimento da população proporcionou um aumento da expectativa média de vida.

Os seus objetivos foram alcançados tendo em vista que se percebeu que as instituições não se encontram preparadas para receber alunos da terceira idade, em nenhum dos seus aspectos: físico, intelectual, emocional, social, cultural e pedagógico. A excelente acessibilidade das instituições de ensino particular para receber alunos com deficiência, terminou por se preparar também para receber a terceira idade.

Não se percebeu outras adaptações realizadas pelas instituições, como pedagógicas, intelectual, emocional e social, aos alunos da terceira idade, salvo a bolsa (desconto), o que se considerou um aspecto positivo da pesquisa. Outro ponto positivo foi que a instituição de ensino superior pública afirmou possuir disciplinas, grupos pesquisas e ações de extensão sobre a terceira idade.

Apesar de se perceber uma boa condição física das instituições particulares, os alunos propuseram algumas adequações, como: "aulas em locais mais baixos, pois todos usam o elevador"; estacionamentos com mais vagas e mais próximos ao local de estudo, inclusive há um NBR específica para este aspecto, a de 2015 
Com relação a outros aspectos, afirmaram, "nas avaliações os alunos de terceira idade, deveriam ser vistos de maneira diferente"; as provas são feitas com letras pequenas; "poderiam ter pessoas específicas para nos motivarem, um programa de incentivo"; há pessoas que chegam com problemas emocionais. Muitos idosos não sabem lidar com computador, deve há mais auxílio com tecnologias e informática, pois muitos moram sozinhos e não possuem facilidades com as ferramentas do computador; não há atendimento para lidar com o fato de que a "cognição do aluno é mais baixa". Nota-se que ainda há o preconceito dos próprios idosos com relação a sua cognição e outras diferenças, o que poderia ser amenizado ou sanado com um atendimento pedagógico diferenciado.

Percebeu-se com este trabalho que ainda não há a preocupação das IES com os alunos idosos. Não existe a percepção de que, com o aumento da expectativa de vida, eles estão cursando o ensino superior, como uma segunda graduação ou como a primeira. Os idosos sentem necessidade de voltar a estudar até porque, segundo um deles. "o cérebro não pode parar". Entretanto, eles chegaram a afirmar, e também os próprios gestores afirmaram isto, que devem ser tratados como qualquer outro aluno.

É muito importante este tipo de pesquisa, para gerar informação para as escolas e para que se preparem. Uma afirmação muito séria percebida foi que alguns afirmaram que as universidades não estão preparadas para lidar com as diferenças, de forma geral.

Deve-se salientar aqui as dificuldades que o grupo teve de conseguir realizar as entrevistas com os gestores e alunos. Devido à pandemia, ficou-se completamente à mercê dos gestores para conseguir os alunos, o que só foi conseguido depois de muitos contatos.

A pesquisa tem por intenção estender os seus resultados a outras instituições de ensino superior do Distrito Federal (DF) e quiçá, do Brasil, pois seus resultados foram significativos e relevantes para as instituições que trabalham com a terceira idade. Novas pesquisas deverão ser realizadas com outras instituições de ensino, nesse sentido. 


\section{REFERÊNCIAS}

ABNT. Associação Brasileira de Normas Técnicas. NBR 9050. Acessibilidade a edificações, mobiliário, espaços e equipamentos urbanos. São Paulo: ABNT, 2015.

ALMEIDA, Simone Aparecida Pinheiro de; OLIVEIRA, Rita de Cássia da Silva. $A$ Educação para e na terceira idade construindo na diversidade: uma inclusão necessária. Pontifícia Universidade Católica do Paraná. Curitiba. 2013. Disponível em: <https://document.onl/documents/a-educacao-para-e-naterceira-idade-construindo-na-especialista-em-educacao.html>. Acesso em: 30 out. 2020.

ARRUDA, I. Análise de uma Universidade da Terceira Idade no município de Campinas. Dissertação (Mestrado) - Curso de Pós-Graduação em Educação, Pontifícia Universidade Católica de Campinas. Campinas, 2009.

BRASIL. Lei no 13.535, de 15 de dezembro de 2017. Disponível em: <http://www.planalto.gov.br/ccivil_03/_Ato2015-

2018/2017/Lei/L13535.htm\#art1>. Acesso em: 31 out. 2020.

. Estatuto do Idoso, Lei no 10.741. Brasília: Planalto, 2013.

BRASIL.IBGE. Projeção da população. Brasil, 2008.

. Projeção da população. Brasil, 2011.

BRASIL.MEC. Lei de Diretrizes e Bases da Educação Nacional (LDB) Lei 9394/96. Brasília: MEC, 1996.

BÚFALO, Katia Silva. Aprender na terceira idade: educação permanente e velhice bem-sucedida como promoção da saúde mental do idoso. Revista Kairós Gerontologia, São Paulo, v. 16, n. 3, p. 195-212, junho. 2013.

BUKSMAN S et al. Sociedade Brasileira de Geriatria e Gerontologia. Quedas em Idosos: Prevenção. 2008. Disponível em: <https://sbgg.org.br/wpcontent/uploads/2014/10/queda-idosos.pdf>. Acesso em: 24 abr. 2019.

CARNEIRO, Rachel Shimba Carneiro; FALCONE, Eliane Mary de Oliveira. O desenvolvimento das habilidades sociais em idosos e sua relação na satisfação com a vida. Estudos de Psicologia, 18(3), julho-setembro/2013, 517-526. Disponível em: <https://www.scielo.br/pdf/epsic/v18n3/12.pdf>. Acesso em: 30 out. 2020.

DF. CODEPLAN. População será de 3,4 milhões em 2030. 2019. Disponível em: <http://www.codeplan.df.gov.br/df-tera-364-milhoes-de-habitante-em-2030/>.

Acesso em: 24 abr. 2019.

FAJARDO, Vanessa. Faculdade da Terceira Idade garante qualidade de vida, dizem idosos. G1, São Paulo. 2010. Disponível em: <http://g1.globo.com/educacao/noticia/2010/06/faculdade-da-terceira-idadegarante-qualidade-de-vida-dizem-idosos.html>. Acesso em: 30 out. 2020.

FREIRE JÚNIOR et al. Estudo da acessibilidade de idosos ao centro da cidade de Caratinga, MG. Rev. Bras. Geriatr. Gerontol., Rio de Janeiro, 2013 p. 541558. Disponível em:<http://www.scielo.br/pdf/rbgg/v16n3/v16n3a12>. Acesso em: 30 abr. 2019

LEMOS, Vinícius. Volta às aulas aos 90 anos: os idosos brasileiros que decidiram ir à faculdade. De Cuiabá para a BBC News Brasil. 2019 Disponível em: <https://www.bbc.com/portuguese/brasil-46704765>. Acesso em: 30 out. 2020.

MINHAVIDA. Quedas: de acidente comum na terceira idade à epidemia. 2008. Disponível em: <https://www.minhavida.com.br/saude/materiais/2567-quedasde-acidente-comum-na-terceira-idade-a-epidemia> Acesso em: 15 abr.2019. 
NATALI, Adriana. Educação na Maturidade. Revista Ensino Superior. 2014. Disponível em: <https://www.semesp.org.br/noticias/educacao-na-maturidade/>. Acesso em: 30 out. 2020.

OMS. Relatório Mundial de Saúde e Envelhecimento. USA: OMS, 2015.

ONU. ONU pede inclusão e políticas públicas para os idosos. 2015. Em dia Internacional. Disponível em:<https://nacoesunidas.org/em-dia-internacionalonu-pede-inclusao-e-politicas-publicas-para-os-idosos/>. Acesso em 24 abr. 2019.

PAPALIA, Diane E.; OLDS, Sally W. Desenvolvimento Humano. Porto Alegre: Artmed, 2013.

REIS, S. M. A. de O.; MEIRE, A. M. T.; MOITINHO, C. R. História de Vida de Idosos no Ensino Superior: percursos inesperados de longevidade escolar. Revista Exitus, Santarém/PA, Vol. 8 № 3, 2018 p. 340-369. Disponível em:<http://www.ufopa.edu.br/portaldeperiodicos/index.php/revistaexitus/article/ view/649>. Acesso em: 28 abr. 2019.

REY, Fernando González. Pesquisa Qualitativa e Subjetividade: os processos de construção da informação. São Paulo: Thomson, 2005.

SALVADOR, César Coll et al. Psicologia da Educação. Porto Alegre: ARTMED, 2010.

SCORTEGAGNA, Paola Andressa; OLIVEIRA, Rita de Cássia da Silva. Educação: integração, inserção e reconhecimento social para o idoso. Revista Kairós Gerontologia, São Paulo, v. 13, n. 1, p. 53-72, junho. 2010. Disponível em: <https://revistas.pucsp.br/kairos/article/download/4858/3440>. Acesso: 30 de out. 2020.

VECCHIA, Roberta Dalla et al. Qualidade de vida na terceira idade: um conceito subjetivo. Rev Bras Epidemiol 2005; 8(3): 246-52. Disponível em: $<$ https://www.scielo.br/pdf/rbepid/v8n3/06.pdf>. Acesso em: 30 out. 2020.

VERAS, Renato Peixoto; CALDAS, Célia Pereira. Promovendo a saúde e a cidadania do idoso: movimento das universidades da terceira idade. Ciência \& saúde coletiva, Rio de Janeiro, v. 9, n. 2, p. 423-432, 2004.

VILELA JUNIOR, Guanis de Barros. Pesquisa Qualitativa. Disponível em:<http://www.guanis.org/metodologia/a_pesquisa_quantitativa.pdf>. Acesso em: 18 abr. 2010.

WHO. WORLD HEALTH ORGANIZATION. Envelhecimento ativo: uma política de saúde. Tradução Suzana Gontijo. - Brasília: Organização Pan-Americana da Saúde, 2005.

CACHIONI, M. Envelhecimento bem sucedido e participação numa Universidade para a Terceira Idade: a experiência dos alunos da Universidade São Francisco. 1998. Dissertação de Mestrado - Faculdade de Educação UNICAMP, 1998. 


\section{APÊNDICES}

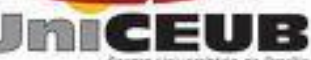

CENTRO UNIVERSITÁRIO DE BRASÍLIA (UniCEUB)

PROGRAMA DE INICIAÇÃO CIENTÍFICA DO UNICEUB

CURSO DE ARQUITETURA E URBANISMO (FATECS)

CURSO DE CIÊNCIAS BIOLÓGICAS (FACES)

ENTREVISTADOR (A)

I_L $/ 2020$.

Nome da Instituição:

\section{ROTEIRO DE ENTREVISTA PARA OS ALUNOS}

1) Dados de identificação do participante:

Sexo: ( ) masculino ( ) feminino

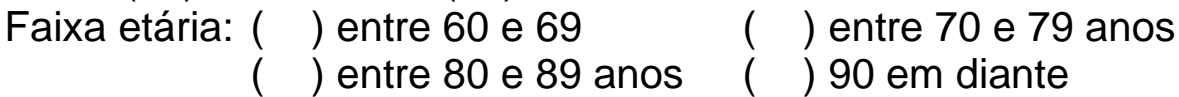

2) Curso que realiza:

3) Já possuía outra graduação? Sim ( ） Não ( )

Se sim, qual?

4) Qual foi ou é a sua profissão?

5) Tempo de realização do curso:

( ) 1 ano

( ) 2 a 3 anos

( ) 4 em diante

Questões

1. Como você se sente, fisicamente, estando na terceira idade?

2. Por que decidiu cursar o ensino superior?

3. Você se encontra satisfeito em seu curso? Explique.

4. Quando ingressou na instituição, teve algum atendimento específico por estar na terceira idade? Qual (ais)?

5. Teve alguma dificuldade na instituição devido à sua idade? Qual? Por quê?

6. Como é o seu relacionamento com os colegas?

7. E com os professores?

8. Existe, na instituição, algum tipo de adaptação física para receber alunos da sua faixa etária? Qual (ais)?

9. Do ponto de vista educacional, você considera que a instituição está preparada para receber pessoas na terceira idade? Por quê?

10. Já precisou de algum atendimento específico relacionado à sua idade na instituição? Qual (ais)?

11. Que sugestões daria à instituição, dos pontos de vista físico, pedagógico, emocional e social para atender à terceira idade? 
PROGRAMA DE INICIAÇÃO CIENTÍFICA DO UNICEUB

CURSO DE ARQUITETURA E URBANISMO (FATECS)

CURSO DE CIÊNCIAS BIOLÓGICAS (FACES)

ENTREVISTADOR (A)

/ $/ 2019$.

\section{ROTEIRO DE ENTREVISTA PARA OS GESTORES}

Nome da Instituição:

1) Dados de identificação do participante:

Sexo: ( ) masculino ( ) feminino

Faixa etária: ( ) entre 30 e $39 \quad$ ( ) entre 40 e 49 anos

( ) entre 50 e 59 anos ( ) 60 em diante

Cargo que ocupa na instituição:

Tempo que exerce este cargo:

Questões

1. Você tem ideia do número de pessoas acima de 60 anos que estudam na instituição?

2. A instituição está preparada para receber esses estudantes? Se sim, de que forma?

3. Foi realizada alguma adaptação na instituição para receber as pessoas da terceira idade? Se sim, qual (ais)?

4. Há alguma preocupação em relação ao ambiente físico para atender à terceira idade? Se sim, qual (ais)?

5. Existe algum outro tipo de preocupação (pedagógica, social, emocional) para atender à terceira idade? Se sim, qual (ais)?

6. Existe algum tipo de tratamento especial para a terceira idade? Se sim, qual (ais)?

7. Alunos na terceira idade podem constituir em um problema para a instituição? Explique.

8. Há algum benefício à instituição em receber alunos na terceira idade? Explique.

9. Já tiveram algum problema relacionado a alunos da terceira idade? Se sim, qual (ais)?

10. Tem algum outro comentário a fazer em relação a alunos da terceira idade, na instituição? 
